\title{
Does the Amount of Jumping with Respect to Positions During Volleyball Matches Affect the Team Success at the End of the Season?
}

\author{
Cengiz Akarcesme ${ }^{1}$, Yaprak Kalemoglu Varol $^{1} \&$ Filiz Colakoglu $^{1}$ \\ ${ }^{1}$ Sport Sciences Faculty, Gazi University, Ankara, Turkey \\ Correspondence: Cengiz Akarcesme, Sport Sciences Faculty, Gazi University, Abant Sokak No: 12, Ankara, \\ Turkey. Tel: 90-532-665-6093.
}

Received: June 30, 2018

Accepted: July 20, 2018 Online Published: September 6, 2018

doi:10.5539/jel.v7n6p81

URL: https://doi.org/10.5539/jel.v7n6p81

\begin{abstract}
In many sports like volleyball, jumping, balance and explosive strength which are biomotor abilities have become more important day by day to succeed. Athletes focus on games at game period so the time that they spend for improving their biomotor abilities can be less. Therefore, performance that obtained in preparation period and sustaining that performance in whole season affect significantly team rank at the end of the season.

In the lights of these informations, the affect of amount of jumps with respect to different positions was investigated in major league of Turkey in 2013-2014. There were 149 female volleyball players between the ages $17-27$ (age $24.19 \pm 2.42$ ) in this study. 12 teams competed with each other and 125 games that is 455 sets were evaluated. Moreover; videos were analyzed three times by experts. Number of jumps in serve, block, spike and setting were recorded. Spearman Brown Order Differential Correlation Coefficient was used for determining the relations between dependent and independent variables and descriptive statistics in analyzing datum. In addition to this, Multiple Linear Regression Analysis was used for investigating regression level between independent and dependent variables. As a result of this, middle blockers jumped the most $(\mathrm{M}=155.86, \mathrm{SD}=39.77)$ while opposites jumped the least $(\mathrm{M}=73.31, \mathrm{SD}=23.49)$. The amount of jumps of wing spikers $(\mathrm{r}=-.130, \mathrm{p}<.05)$ and middle blockers $(\mathrm{r}=-.185, \mathrm{p}<.01)$ was negatively related with team success at the end of the season in low level. The total amount of jumps in different positions was negatively related with team success at the end of the season in low level too $(r=-.156, p<.01)$. Setters, wing spikers, middle blockers and opposites were listed with respect to regression factor $(\boldsymbol{B})$ and their importance level for team success at the end of the league. In conclusion, number of jumps in different positions at game time affects team success positively.
\end{abstract}

Keywords: volleyball, team success, jumping, wing spiker, middle blocker, setter, opposite

\section{Introduction}

Volleyball is an "interval" sport, physiologically, which has many short-time and high intensity of exercise periods with short rests and plenty of explosive practices such as spike and block, physiologically (Sheppard et al., 2007; Sheppard et al., 2009; Gabbett \& Georgieff, 2007). At higher levels, technical performance is limited not only by physical specialties but also by physical suitability, speed and vertical jump performance (Sheppard et al., 2007; Smirth, Robets, \& Watson, 1992). In this report, body height, length of body parts and vertical jump skills are significant for athlete's success in attack and block (Viitasalo, 1982). In volleyball, jumping performance which is usually used in spike, block and serve which are some technical elements of volleyball is an important parameter (Ziv \& Lidor, 2010; Kenny \& Gregory, 2006; Reeser \& Bahr, 2003; Coleman, Benham \& Northcott, 1993). Jumping takes place in serves the starter of game, sets to the attackers, attacks for points, blocks which is used for preventing opponents' attack and counterattacks after defense, respectively (FIVB, 1989; FIVB, 1992).

In volleyball like in many other sports, while the purposes of preparation period are to improve technical performance, physical suitability, speed and vertical jump performance, tactical staff and friendly games are not the main purposes on that time. On the contrary, in competition period there are two main focuses which are tactical staff and friendly games. Due to spending many times on these two, the time which is spent for improving technical performance, physical suitability, speed and vertical jump performance can be decreased. 
Because of this reason, well planned preparation period practices are necessary to improve athlete's skills. In addition to this, these improved skills should be prevented in whole season. They affect the team rank. There are not many studies about volleyball players' biomotor performance analysis during games (Hakkinen, 1993).

In the lights of this information, the purpose of this study is to investigate affects on team rank at the end of the season of jumping numbers during game time with respect to positions. All teams played in Women' First League in Turkey.

\section{Method}

\subsection{Research Model}

Relational research model was used in this research. The purpose of this study is to investigate the affect on team rank of jumping numbers with respect to positions in the 2013-2014 season.

\subsection{Research Group}

Study included 149 women with between the ages 17-27 (age 24.19 \pm 2.42 ) from 12 teams. There were 111,633 jumping which happened during 125 games; that is; 455 sets (3-0, 3-1, 3-2) and during serve, block, spike and jumping set. In league time, all games were recorded by researchers. Then, experts watched games three times to analyze and to count the number of jumps with respect to different positions.

\subsection{Analyzing Data}

Before analyzing research data, their distribution was considered. Lilliefors Kolmogorov-Smirnov shows that research data are not distributed regular $(\mathrm{p}<.05)$. Histogram graph and normal distribution curve were obtained and analyzed by Skewness $(+1$ and -1$)$ and Kurtosis $(+2$ and -2$)$. Spearman Brown formula was used for investigating the relations between definitive statistics in analyzing (numbers, arithmetic mean and standard deviation) and dependent and independent variables. In addition to this, Multiple Linear Regression Analysis was used for investigating the level that independent variables predict dependent variables. In these analyses, while the number of jumps with respect to different position was taken as independent variables, team ranks at the end of the season were taken as dependent variables. The significance level was taken as 0.01 and 0.05 to understand data. These data were analyzed by SPSS for Windows 23 software package.

\section{Results}

There are means and standard deviations related with the number of jumps with respect to different positions in Table 1.

Table 1. Number of jumps in terms of different position

\begin{tabular}{lccc}
\hline Variables & $\mathbf{n}$ & $M$ & SD \\
\hline Wing spiker & & 121.04 & 32.87 \\
Middle blocker & & 155.86 & 39.77 \\
Opposite & 125 & 73.31 & 23.49 \\
Setter & & 96.33 & 29.77 \\
Total & & 446.60 & 112.48 \\
\hline
\end{tabular}

Examining Table 1, while middle blockers jumped most, opposites jumped least in whole season $(\mathrm{M}=73.31$, $\mathrm{SD}=23.49$ ).

Table 2. The relationship between the number of jumps in terms of positions and season-end team success

\begin{tabular}{lllllll}
\hline Variables & $\begin{array}{l}\text { Team rank at the } \\
\text { end of the season }\end{array}$ & $\begin{array}{l}\text { Wing } \\
\text { spiker }\end{array}$ & $\begin{array}{l}\text { Middle } \\
\text { blocker }\end{array}$ & Opposite & Setter & Total \\
\hline Team Rank At The End of The & - & & & & & \\
Season & $-.130^{*}$ & - & & & \\
Wing Spiker & $-.185^{* *}$ & $.824^{* *}$ & - & & - \\
8sm Middle Blocker & -.116 & $.710^{* *}$ & $.712^{* *}$ & - & $.553^{* *}$ & - \\
Opposite & -.061 & $.723^{* *}$ & $.766^{* *}$ & $.856^{* *}$ & - \\
Setter & $-.156^{*}$ & $.916^{* *}$ & $.943^{* *}$ & $.802^{* *}$ & .8 & \\
Total & & & & &
\end{tabular}

$*=\mathrm{p}<.05, * *=\mathrm{p}<.01$. 
Table 2 shows that wing spikers' and middle blockers' jumping numbers related negatively and low with the team rank at the end of the season. Moreover, all positions' total jumping numbers related negatively and low with the team rank at the end of the season.

Table 3. Analysis of the teams' prediction of the season-end success

\begin{tabular}{llllllll}
\hline Variables & $\mathbf{B}$ & $\begin{array}{l}\text { Standard } \\
\text { error }\end{array}$ & $\mathbf{B}$ & $\mathbf{t}$ & $\mathbf{p}$ & $\begin{array}{l}\text { Part } \\
\mathbf{r}\end{array}$ & $\begin{array}{l}\text { Partial } \\
\mathbf{r}\end{array}$ \\
\hline Constant & 8.696 & .906 & & 9.600 & $.000^{*}$ & - & - \\
Wing spiker & .023 & .020 & .220 & 1.185 & .237 & -.120 & .076 \\
Middle blocker & .027 & .018 & .200 & 1.087 & .223 & -.118 & .063 \\
Opposite & .018 & .020 & .121 & .911 & .363 & -.123 & .058 \\
Setter & .037 & .019 & .318 & 1.937 & .054 & -.075 & .123 \\
Total & -.022 & .011 & -.717 & -2.043 & .042 & -.129 & -.129 \\
\hline $\mathbf{R}=0.186$ & $\mathbf{R}^{2}=0.035$ & & & & & & \\
$\mathbf{F = 2 . 2 0 4}$ & $\mathbf{p}=.000$ & & & & & & \\
\hline
\end{tabular}

When the analysis results in Table 3 are examined, it is seen that the jumping numbers of the volleyball players playing in different positions are a significant predictor of the team's season-end success $\left(R=0.186, R^{2}=0.04\right.$, $\mathrm{p}<.01)$. The jumping numbers of the volleyball players in different positions in the match explains $4 \%$ of the total variance on the team's season-end success. According to standardized regression coefficient (B), significance levels of the predictive variables on team's season-end success were; total, setter, wing spiker, middle blocker and opposite, respectively. From the point of significance of regression coefficient, opposites', setters' wing spikers' and middle blockers' jumping numbers are not important predictor. In line with all these findings, it was identified that the jumping numbers of the volleyball players playing in different positions have a low affect on the team's season-end success.

\section{Discussion}

The purpose of this study is to investigate the affects of jumping numbers during game time with respect to positions on team rank at the end of the season. All teams played in Women' First League in Turkey. Results are shown as middle blockers jumped most $(\mathrm{M}=155.86, \mathrm{SD}=39.77)$ and opposites jumped least $(\mathrm{M}=73.31$, $\mathrm{SD}=23.49$ ) in Table 1 which is located in Results part. In modern volleyball, there are six players which consist of 2 middle blockers, 2 wing spikers, 1 setter, 1 opposite and libero who changes with middle blocker after he/she serves. Therefore, according to table 1 result's jumps of middle blockers and wing spikers are done by two players in same positions.

Table 2 shows that wing spikers' $(r=-.130, \mathrm{p}<.05)$ and middle blockers' $(r=-.185, \mathrm{p}<.01)$ jumping numbers related negatively and low with the team rank at the end of the season. Moreover, all positions' total jumping numbers related negatively and low with the team rank at the end of the season $(r=-.156, p<.01)$.

Table 3 shows that jumping numbers of different positions are significant regression element of team rank at the end of the season most $\left(\mathrm{R}=0.186, \mathrm{R}^{2}=0.04, \mathrm{p}<.01\right)$.

In some researches, athletes do 250-300 movements which affect especially their leg muscles during games. These movements are divided as jumps \%50-60, fast movements and transpositions $\% 30$ and falls $\% 15$ (Stojanovic \& Kostic, 2002). When they are considered with respect to positions, setters are active in terms of jumps no matter that they are front or back player. Especially setters prefer jumping sets for the balls really close to the net in order to fake opponent's' middle blockers and to set easily in difficult conditions (FIVB, 1989).

In jumping sets, the distance between setter and attacker gets closer so spikers can attack more quickly than non-jumping sets. This situation aggravates opponent's middle blockers' block. In this case, opponent's middle blockers' pause or one to one jump enables second tempo attackers' attack. Moreover, combinations and back attack corridors can be used effectively by jump sets (Fraser, 1988).

In setter front rotations, setter can jump for block or attack. In setter back rotations, they can jump for jump serves or setting. In addition to this, they prefer jump sets to fake opponent's middle blockers and to set the game faster and higher in case of good reception and defense. Opposites and wing spikers jump for block, attack when they are front players. Also, they jump for back attacks and serves when they are back players. Middle blockers jump for block and attack when they are close to the net while they jump only for serve when they are back 
players. Furthermore, they have to jump for tricking other middle blocker whether they get the set or not (Viitasalo et al., 1987).

In five sets game, there are many movements which need high level strength (Cinemre \& Unver, 2013). In volleyball, bottom and upper extremity are used repetitively and overexerted. Hence, some physical suitability and performance parameters should be analyzed and studied in order to evaluate the body movement skill level, suitability to sport and performance. Volleyball players' jump skills should be higher than average to beat their opponents and to be successful. Since, jumping skill is one of the most important disputable reason which affects the success in volleyball, according to volleyball coaches and players (Sheppard, Newton, \& McGuigan, 2007; Challoumas \& Artemiou, 2018; Kitamura et al., 2017).

As a result, it is necessary to do disciplined and long time period work when considered the factors of success in volleyball. The skills which gained in practices in preparation period should be preserved and continued in whole season because the success factors range widely, which affects the team rank at the end of the season. It corrects the study hypothesis.

In this sense, this research is counted as important for sport scientists because studies related with volleyball players' performance during games are limited. Even though there are many articles about jumping numbers of volleyball players, there is not any study investigating the affects of jumping numbers during game time with respect to positions on team rank at the end of the season. Also, it can be at the fore for following studies. If these studies find out the purposes of jumps during games, detailed analyze of players who play in different positions will be possible. It is crucial for both coaches and players.

\section{References}

Challoumas, D., \& Artemiou, A. (2018). Predictors of attack performance in high-level male volleyball players. International Journal of Sports Physiology and Performance, 24, 1-23. https://doi.org/10.1123/ijspp.2018-0125.

Cinemre, A., \& Ünver, E. (2013). Voleybolda Kuvvet ve Güç Antrenmanları. 5. Antrenman Bilimi Kongresi, Ankara, Turkey.

Coleman, S. G., Benham, A. S., \& Northcott, S. R. (1993). A three-dimensional cinematographical analysis of the volleyball spike. Journal of Sports Sciences, 11(4), 295-302. https://doi.org/10.1080/02640419308729999.

FIVB. (1989). Technical Review for Volleyball Coaches. International Volley Tech. 28.

FIVB. (1992). Technical Review for Volleyball Coaches. International Volley Tech, 11.

Fraser, S. D. (1988). Strategies for Competetive Volleyball. Champaign, IL: Leisure Press.

Freitas, V. H., Nakamura, F. Y., Miloski, B., Samulski, D., \& Bara-Filho, M. G. (2014). Sensitivity of physiological and psychological markers to training load intensification in volleyball players. Journal of Sports Sciences and Medicine, 13(3), 571-579.

Gabbett, T., \& Georgieff, B. (2007). Physiological and anthropometric characteristics of Australian junior national, state, and novice volleyball players. Journal of Strength and Conditioning Research, 21(3), 902-908. https://doi.org/10.1519/R-20616.1

Häkkinen, K. (1993). Changes in physical fitness profile in female volleyball players during the competitive season. Journal of Sports Medicine and Physical Fitness, 33(3), 223-232.

Hippolyte, R., \& Blacklaws, M. (1997). Setting from The Mechanics to Art. Scone: Dark Horse Publishing.

Kenny, B., \& Gregory, C. (2006). Voleyball: Step to Success. USA: Human Kinetics.

Kitamura, K., Pereira, L. A., Kobal, R., Cal Abad, C. C., Finotti, R., Nakamura, F. Y., \& Loturco, I. (2017). Loaded and unloaded jump performance of top-level volleyball players from different age categories. Biology of Sport, 34(3), 273-278. https://doi.org/ 10.5114/biolsport.2017.67123

Reeser, J. C., \& Bahr, R. (2003). Handbook of Sports Medicine and Sience: Volleyball. Malden, MA: Blackwell Science. https://doi.org/10.1002/9780470693902

Sheppard, J. M., Cronin, J. B., Gabbett, T. J., Mcguigan, M. R., Etxebarria, N., \& Newton, R. U. (2008). Relative importance of strength, power, and anthropometric measures to jump performance of elite volleyball players.

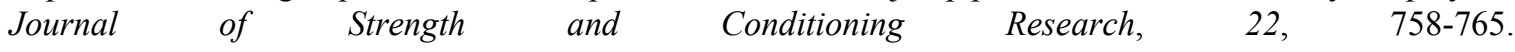
https://doi.org/10.1519/JSC.0b013e31816a8440 
Sheppard, J. M., Gabbett, T., Taylor, K. L., Dorman, J., Lebedew, A. J., \& Borgeaud, R. (2007). Development of a repeated-effort test for elite men's volleyball. International Journal of Sports Physiology and Performance, 2(3), 292-304. https://doi.org/10.1123/ijspp.2.3.292

Sheppard, J. M., Gabbett, T. J., \& Stanganelli, L. C. (2009). An analysis of playing positions in elite men's volleyball: considerations for competition demands and physiologic characteristics. Journal of Strength and Conditioning Research, 23, 1858-1866. https://doi.org/10.1519/JSC.0b013e3181b45c6a

Sheppard, J. M., Newton, R., \& McGuigan, M. (2007). The effects of accentuated eccentric load on jump kinetics in high-performance volleyball players. International Journal of Sports Science and Coaching, 2(3), 267-284. https://doi.org/10.1260/174795407782233209

Smith, D. J., Roberts, D., \& Watson, B. (1992). Physical, physiological and performance differences between Canadian national team and universiade volleyball players. Journal of Sports Sciences, 10(2), 131-138. https://doi.org/10.1080/02640419208729915

Stojanovic, T., \& Kostić, R. M. (2002). The effects of the plyometric sport training model on the development of the vertical jump of volleyball players. Facta Universitatis-Series: Physical Education and Sport, 1(9), $11-25$.

Viitasalo, J. T. (1982). Anthropometric and physical performance characteristics of male volleyball players. Can Journal of Applied Sport Sciences, 7(3), 182-188.

Viitasalo, J. T., Rusko, H., Pajala, O., Rahkla, P., Ahila, M., \& Montonen, H. (1987). Endurance requirements in volleyball. Canadian Journal of Applied Sport Sciences, 12(4), 194-201.

Ziv, G., \& Lidor, R. (2010). Vertical jump in female and male volleyball players: a review of observational and experimental studies. Scandinavian Journal of Medicine \& Science in Sports, 20(4), 556-567. https://doi.org/10.1111/j.1600-0838.2009.01083.x

\section{Copyrights}

Copyright for this article is retained by the author, with first publication rights granted to the journal.

This is an open-access article distributed under the terms and conditions of the Creative Commons Attribution license (http://creativecommons.org/licenses/by/4.0/). 